\title{
A Study of Osmosis Rate Through Several Proton Conducting Polymer Composite Membranes
}

\author{
Reinis KAPARKALĒJS ${ }^{1,2}{ }^{*}$, Einārs SPRŪG̣IS ${ }^{1,2}$, Guntars VAIVARS ${ }^{1,2}$ \\ ${ }^{1}$ Institute of Solid State Physics, University of Latvia, Kengaraga Str. 8, LV-1063, Riga, Latvia \\ ${ }^{2}$ Faculty of Chemistry, University of Latvia, Jelgavas Street 1, LV-1004, Riga, Latvia \\ crossref http://dx.doi.org/10.5755/j02.ms.27892
}

\section{Received 07 December 2020; accepted 01 February 2021}

\begin{abstract}
Carbon dioxide is typically considered to be a byproduct of various industrial processes that should not be released into the environment due to its nature as a harmful greenhouse gas. One of the more promising ways to dispose of it in an economical and environmentally friendly way is by using it as a raw material in electrochemical synthesis reactors. An important part of such reactors is an ion exchange membrane. In this study the influence of $\mathrm{ZrO}_{2}$ content in SPEEK - $\mathrm{ZrO} 2$ composite membranes on rate of osmosis trough them was investigated, with the goal of evaluating $\mathrm{ZrO}_{2}$ as an additive for making ion exchange membranes with fine-tuned osmotic permeability.

Keywords: sulfonated polyetheretherketone, zirconium dioxide, composite membrane, ion exchange membrane, osmosis.
\end{abstract}

\section{INTRODUCTION}

Nowadays a large amount of attention is given to finding ways in which to minimize the greenhouse effect. The main way in which to achieve this is reducing the amount of $\mathrm{CO}_{2}$ released during various industrial processes as well as increasing their general energy efficiency [1]. $\mathrm{CO}_{2}$ electrochemical reduction cells are some of the more promising options in this regard, as they can efficiently turn waste $\mathrm{CO}_{2}$ into valuable industrial precursors [2].

One of such projects is CO2EXIDE, which aims to turn $\mathrm{CO}_{2}$ and water into ethylene and hydrogen peroxide in energy-efficient electrochemical synthesis reactors [3]. From the obtained ethylene and hydrogen peroxide it is possible to obtain useful industrial precursor chemicals, such as ethylene oxide [4], which helps make the entire process economically viable.

An important component such a reactor requires is the ion exchange membrane, which allows the concentration of electrolyte to be different in cathode and anode compartments, as well as prevents compounds created during synthesis from mixing and reacting with each other [5]. Currently Nafion membranes are most often used for this purpose, since they possess excellent physical and chemical stability, as well as high water and ion transmittance, but their high production costs are incentivizing a search for cheaper alternatives [6, 7].

Some of the more promising alternatives to Nafion membranes are sulfonated polyetheretherketone (SPEEK) membranes and their composites. While their durability and transmittance are yet to match Nafion's, they are typically much cheaper to make and new types with improved properties are being actively investigated [8-10].

A potential way of improving SPEEK membrane properties is by creating SPEEK - zirconium dioxide composite membranes. Adding $\mathrm{ZrO}_{2}$ to the membranes reduces swelling in water, water permeability and helps improve their mechanical durability, which is important due to the stresses caused by the high osmotic pressure in an electrochemical cell [11].

In this work the rate of osmosis through SPEEK $-\mathrm{ZrO}_{2}$ composite membranes and a reference Nafion membrane, were compared, with the goal of evaluating the effects of $\mathrm{ZrO}_{2}$ content on the rate of osmosis through the composite membranes.

\section{EXPERIMENTAL DETAILS}

\subsection{Membrane preparation}

SPEEK used for membrane preparation was prepared locally by sulfonating PEEK (Sigma Aldrich, number average molecular weight $\mathrm{Mn} \sim 10300$, weight average molecular weight $\mathrm{Mw} \sim 20800$ ) in concentrated sulfuric acid (Sigma Aldrich, 95-97\%) [12]. A scheme of this process can be seen in Fig. 1. Degree of sulfonation was determined by using the titration method [13] and calculated to be $0.71 \pm 0.05$.

SPEEK - $\mathrm{ZrO}_{2}$ membranes were prepared by dissolving SPEEK and the necessary amount of $\mathrm{ZrO}_{2}$ (Sigma Aldrich, $5 \%$ nanosuspension in water) in dimethylformamide (Sigma Aldrich). The solution was heated and stirred until SPEEK was completely dissolved, then poured out on a glass base, spread with a doctor blade, and dried in an oven at $80{ }^{\circ} \mathrm{C}$ for around 24 hours. Before testing the thickness of each membrane was measured with a micrometer (Tesa Micromaster electric micrometer, $\pm 1 \mu \mathrm{m})$.

\subsection{Osmosis rate measurements}

Rate of osmosis was measured indirectly, by measuring electrical conductivity of a potassium bicarbonate solution

\footnotetext{
* Corresponding author. Tel.: +371 20144948.

E-mail address: reinis.kaparkalejs@lu.lv (R. Kaparkalējs)
} 
<smiles>COc1ccc(Oc2ccc(C(=O)c3ccc(C(C)C)cc3)cc2)cc1</smiles>

Fig. 1. PEEK sulfonation, $n=$ degree of sulfonation

(Sigma Aldrich, solutions prepared locally) in one side of the experimental cell (Fig. 2.) with a conductometer (Metrohm $914 \pm 0.1 \mathrm{mS} / \mathrm{cm}$ ). $\mathrm{KHCO}_{3}$ was chosen since it is the electrolyte used in the planned CO2EXIDE electrochemical synthesis reactors, and as such best represents the environment in which the membranes are likely to be used. Concentration of the solution at any one time was calculated by using a previously taken standard curve (Fig. 3).

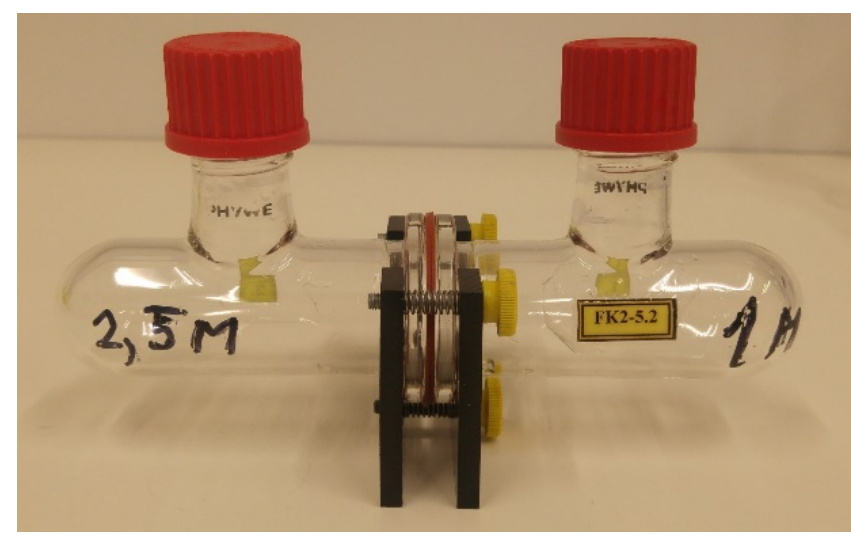

Fig. 2. Osmosis and electrochemistry cell Phywe

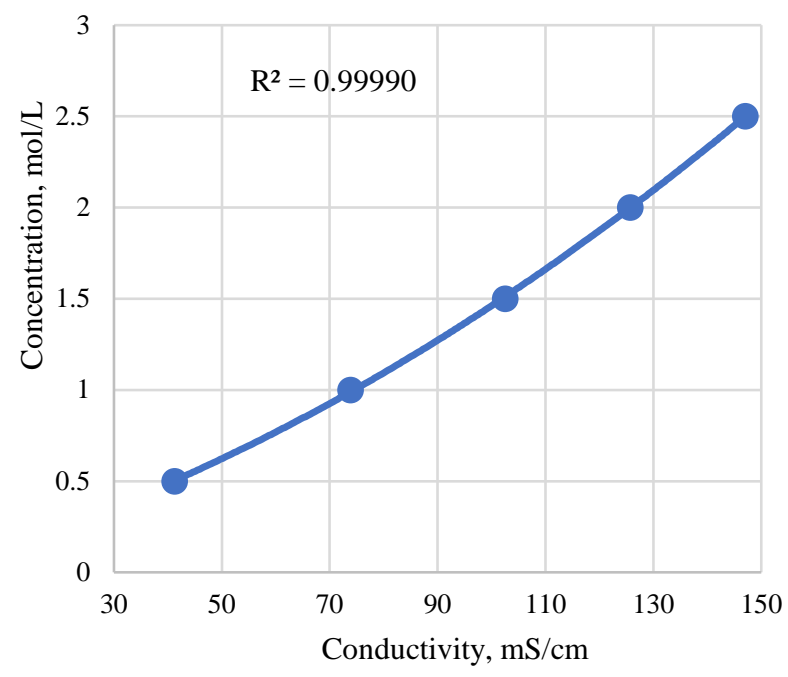

Fig. 3. $\mathrm{KHCO}_{3}$ solution standard curve

The membranes were secured between the two sides of the cell and $42 \mathrm{ml}$ of the electrolyte solution were poured in each side (2.5 $\mathrm{M} \mathrm{KHCO}_{3}$ in one side, $1.0 \mathrm{M} \mathrm{KHCO}_{3}$ in the other). Conductivity measurements were carried out around once every hour in the first three hours of the experiment and around once every 24 hours after that. Conductivity was only measured in the side with the higher electrolyte concentration since depth of the solution on the opposite side rapidly became too low for accurate measurements.

\section{RESULTS}

\subsection{Solution concentration changes over time}

Equations of individual solution's concentrations over time were obtained from the experimental data, but, since each membrane had a different thickness and only the relation between $\mathrm{ZrO}_{2}$ concentration and rate of osmosis trough them is relevant in this case, relative concentrations at any point in time need to be obtained before comparisons can be made.

To do this, first, the concentration change rate at any point in time was calculated from the obtained data. Then the obtained rates were multiplied by relative thickness of each membrane and the obtained relative rates used to calculate the relative $\mathrm{KHCO}_{3}$ concentration at every point in time, as seen in Eq. 1:

$c_{\text {rel }}=c_{0}-\Delta c \cdot \frac{b}{b_{0}}$,

where $c_{\text {rel }}$ is the relative $\mathrm{KHCO}_{3}$ solution concentration, $\mathrm{mol} / \mathrm{L} ; c_{0}$ is the starting $\mathrm{KHCO}_{3}$ solution concentration, $\mathrm{mol} / \mathrm{L} ; \Delta c$ is the concentration change rate, $\mathrm{mol} / \mathrm{L} ; b_{0}$ is the reference membrane thickness, $\mu \mathrm{m} ; b$ is the membrane thickness, $\mu \mathrm{m}$.

The obtained relative rates of osmosis over time and based on concentration changes have been shown in Fig. 4.

\subsection{Osmosis rate comparisons}

For ease of comparing relative osmosis rates of membranes, a concentration interval was chosen in which they were all stable (the osmosis was still actively ongoing) and the average osmosis rate in this interval calculated.

The selected $\mathrm{KHCO}_{3}$ concentration interval was from $2.35 \mathrm{~mol} / \mathrm{L}$ to $1.87 \mathrm{~mol} / \mathrm{L}$. The graph showing the correlation between $\mathrm{ZrO}_{2}$ content of the SPEEK - $\mathrm{ZrO}_{2}$ composite membranes and relative rate of osmosis is shown in Fig. 5.

A strong linear correlation can be seen between the $\mathrm{ZrO}_{2}$ content of the membranes and average rate of osmosis. This shows promise for using $\mathrm{ZrO}_{2}$ as an additive for membranes used in electrochemical synthesis reactors, since the ability to precisely and easily adjust rate of osmosis trough them to fit the requirements imposed by any given application can be extremely valuable. 

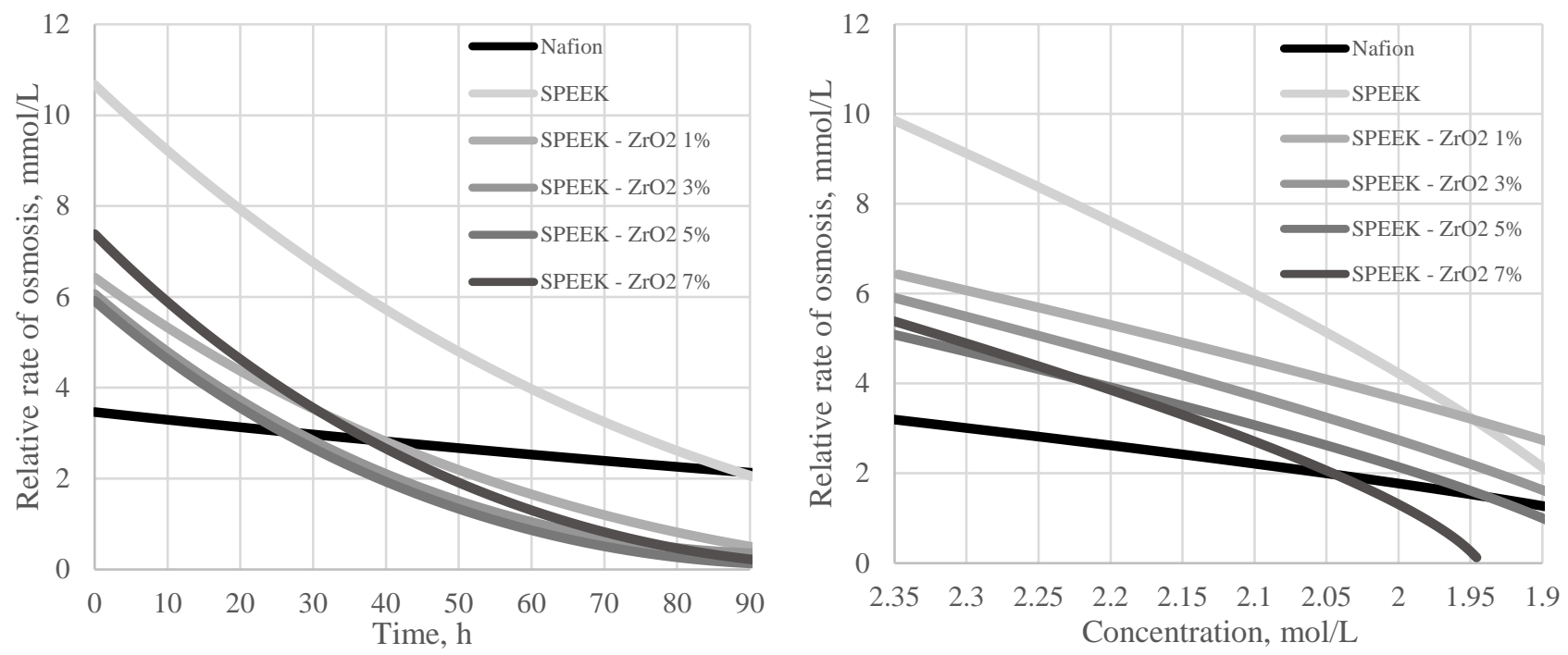

Fig. 4. Relative rates of osmosis through the various membranes over time and based on concentration changes



Fig. 5. Rate of osmosis through SPEEK - $\mathrm{ZrO}_{2}$ composite membranes depending on their $\mathrm{ZrO}_{2}$ content

\section{CONCLUSIONS}

Rate of osmosis through SPEEK - $\mathrm{ZrO}_{2}$ composite membranes exhibits a linear correlation with their $\mathrm{ZrO}_{2}$ content in the $0-7 \% \mathrm{ZrO}_{2}$ content interval, with higher concentrations leading to reduced rate of osmosis. This property can be used to obtain membranes with fine-tuned osmotic properties, which are likely to be useful in electrochemical synthesis reactors and other applications where separating electrolytes of different concentrations is necessary.

\section{Acknowledgments}

The research included in this publication received funding from European Union's Horizon 2020 Research and Innovation Program project under grant agreement No. 768789.

\section{REFERENCES}

1. Yamasaki, A. An Overview of $\mathrm{CO}_{2}$ Mitigation Options for Global Warming - Emphasizing $\mathrm{CO}_{2}$ Sequestration Options Journal of Chemical Engineering of Japan. 36 (4) 2003: pp. $361-375$. https://doi.org/10.1252/jcej.36.361

2. Nitopi, S., $\quad$ Bertheussen, E., $\quad$ Scott, S.B., $\quad$ Liu, X., Engstfeld, A.K., Horch, S., Seger, B., Stephens, I.E.L., Chan, K., Hahn, C., Nørskov, J.K., Jaramillo, T.F., Chorkendorff, I. Progress and Perspectives of Electrochemical $\mathrm{CO}_{2}$ Reduction on Copper in Aqueous Electrolyte Chemical Reviews $119(12)$ 2019: pp. $7610-7672$. https://doi.org/10.1021/acs.chemrev.8b00705

3. About - CO2EXIDE http://www.co2exide.eu/ (accessed Jan 19, 2020).

4. Rebsdat, S., Mayer, D. Ethylene Oxide. In Ullmann's Encyclopedia of Industrial Chemistry, American Cancer Society, 2001. https://doi.org/10.1002/14356007.a10_117

5. Tanaka, Y. Ion Exchange Membranes: Fundamentals and Applications, Second edition.; Elsevier: Amsterdam, Netherlands, 2015.

6. Mauritz, K.A., Moore, R. B. State of Understanding of Nafion Chemical Reviews 104 (10) 2004: pp. 4535-4586. https://doi.org/10.1021/cr0207123

7. Hickner, M.A., Ghassemi, H., Kim, Y.S., Einsla, B.R., McGrath, J.E. Alternative Polymer Systems for Proton Exchange Membranes (PEMs) Chemical Reviews 104 (10) 2004: pp. 4587-4612. https://doi.org/10.1021/cr020711a

8. Reyna-Valencia, A., Kaliaguine, S., Bousmina, M. Tensile Mechanical Properties of Sulfonated Poly(Ether Ether Ketone) (SPEEK) and BPO4/SPEEK Membranes Journal of Applied Polymer Science 98 2005: pp. 2380-2393. https://doi.org/10.1002/app.22417

9. Wu, X., Wang, X., He, G., Benziger, J. Differences in Water Sorption and Proton Conductivity between Nafion and SPEEK Journal of Polymer Science Part B: Polymer Physics 49 (20) 2011: pp. 1437-1445.

https://doi.org/10.1002/polb.22326 
10. Ghasemi, M., Daud, W.R.W., Ismail, A.F., Jafari, Y., Ismail, M., Mayahi, A., Othman, J. Simultaneous Wastewater Treatment and Electricity Generation by Microbial Fuel Cell: Performance Comparison and Cost Investigation of Using Nafion 117 and SPEEK as Separators Desalination 325 2013: pp. 1-6.

https://doi.org/10.1016/j.desal.2013.06.013

11. Silva, V., $\quad$ Ruffmann, B., $\quad$ Silva, H., $\quad$ Mendes, A., Madeira, M., Nunes, S. Zirconium Oxide Modified Sulfonated Poly (Ether Ether Ketone) Membranes for Direct Methanol Fuel Cell Applications Materials Science Forum 455-456 2004: pp. 587-591.
https://doi.org/10.4028/www.scientific.net/MSF.455456.587

12. Luo, H., Vaivars, G., Mathe, M. Double Cross-Linked Polyetheretherketone Proton Exchange Membrane for Fuel Cell International Journal of Hydrogen Energy 37 (7) 2012: pp. 6148-6152. https://doi.org/10.1016/j.ijhydene.2011.05.115

13. Huang, R.Y.M., Shao, P., Burns, C.M., Feng, $X$. Sulfonation of Poly(Ether Ether Ketone)(PEEK): Kinetic Study and Characterization Journal of Applied Polymer Science 82 (11) 2001: pp. 2651-2660. https://doi.org/10.1002/app.2118

(C) Kaparkalējs et al. 2021 Open Access This article is distributed under the terms of the Creative Commons Attribution 4.0 International License (http://creativecommons.org/licenses/by/4.0/), which permits unrestricted use, distribution, and reproduction in any medium, provided you give appropriate credit to the original author(s) and the source, provide a link to the Creative Commons license, and indicate if changes were made. 